balance of payments, no less than a third of the toll on British reserves was caused by export of capital, a good proportion of which consisted of emigrants' funds and money invested in Dominion securities. Moreover, by accentuating the scarcity of manpower in industries where the shortage is already keen, emigration tends to promote inflationary pressure.

The policy best calculated to help Britain overcome the crisis is one which would welcome appropriate grades of immigrants from the continent of Europe. A high rate of immigration makes up for a low degree of internal mobility. The argument that these newcomers would be a strain on the British economy since they have to be fed and housed does not bear analysis. They are prepared to work in industries producing the most essential output-coal, textiles, food-and they are accommodated in existing premises. The value of the marginal product of immigrant labour of this kind much exceeds the cost of the imports and capital equipment needed for its employment.

Finally, there is the long-run question whether Britain can hope to sustain a population of fifty million at anything like the old standard of living when outside help is no longer available. Much will depend on the future course of the terms of trade. There are strong reasons for taking a pessimistic view. The industrializing of agricultural countries will tend to reduce exports of food from these coun. tries. A study of the stages through which the United States has passed is instructive. In poor countries like India, the peasants may sell less of their crops on the market as the price improves; they will wish to consume more themselves. Then, the principle of 'fair shares' in the allocation of food as between rich and poor nations augurs ill for the highly industrialized countries like Britain. These tendencies operating unchecked mean a continuance of dear food for the British people: whether this can be masked indefinitely by a policy of internal subsidies is questionable.

On the other hand, it may be that the world is on the eve of a great advance in the application of science to crop production. Moreover, the long-term trend in consumption habits noted in the inter-war period may yet reassert itself. The most reasonable expectation is that the terms of trade for Britain will fall somewhat from their present level, but will never again reach the favourable ratio experienced between the two World Wars. If the people respond to this stern challenge by increasing and rearranging their productive power, there is no reason why a tolerable equilibrium cannot be found for a population of fifty million. There need be no mass emigration.

In the third paper in the symposium, Mr. R. R. Rawson considered in detail the factors determining White settlement in Kenya and Rhodesia. Looking to the future, he saw signs of a more considerable White settlement in East Africa for strategic reasons; but in view of the lack of mineral resources in Kenya, such a plan would entail linking Kenya with the coal and iron deposits of Rhodesia.

The open discussion ranged widely over the ground covered by the three papers. One of the questions treated in detail was the future of the terms on which Britain can expect to purchase imported food. Reference was made to the views of authorities in other Sections of the British Association, who had pointed out that the effective supply of food could be greatly increased if the heavy loss due to destruc- tion by vermin could be partly eliminated. It was significant to observe the attention devoted to the food problem in this symposium, as in other sessions during the British Association meeting at Brighton. On the question of the White Australia policy, a representative of Section $H$ (Anthropology) disagreed with Prof. Fawcett and argued that the difficulties of assimilating coloured peoples must not be shirked. Finally, I had the feeling that Prof. Fawcett's suggestion that Australia could increase her population to $30-50$ million, and Canada to 60-100 million, was much too optimistic. A careful assessment of the probable economic trends seems to be necessary before such estimates can be put forward with any confidence.

Brinley Thomas

\section{PHYSICAL CHEMISTRY OF PROCESS METALLURGY}

$T$

HE discussion on "The Physical Chemistry of Process Metallurgy", which the Faraday Society held at Ashorne Hill, Warwickshire, during September 23-25, showed plainly that process metallurgy is now as much the province of the physical chemist as the metallurgist. Attention at this meeting was devoted almost entirely to the high-temperature processes involved in the winning and refining of metals, and here in particular it seems that advances will come mainly from the application of physical chemistry. Indeed, speaking as a steelmaker, Sir Andrew McCance (Colvilles, Ltd.) confirmed, in his introductory remarks, that the advances in the openhearth process over the past twenty years have come almost entirely from the physico-chemical approach to open-hearth reactions. In this article it is intended to touch only upon the main topics of physico-chemical interest. In so short a space it is impossible to consider all the problems discussed, and reference will not be made to those papers concerned with industrial applications.

After an opening paper by Sir Charles Goodeve (British Iron and Steel Research Association), outlining the physico-chemical principles of special importance in this field, the subject was considered in three main sections: metallic solutions; roasting and reduction processes; and slags and refining processes. In addition, a number of papers dealt with the problems associated with experimental work in the important temperature-range between $1,000^{\circ} \mathrm{C}$. and $2,000^{\circ} \mathrm{C}$. The main difficulty in handling substances at these high temperatures is finding refractory containers which will not react with them. Almost all substances become chemically reactive in such extreme conditions, since high activation energies for molecular processes are no longer seriously restrictive. Another less obvious problem, which has caused large errors in the results of many equilibrium studies between gas mixtures and metals or slags, is thermal diffusion. This is caused by the large temperature gradients which are generally unavoidable in any apparatus operating under these conditions. The heavier components in the gas mixtures used diffuse away from the hot zone, and so set up concentration differences in the apparatus which may be maintained even under steady flow conditions. These differences can be avoided by combining adequate preheating of the incoming gas with a flow-rate sufficient to prevent any significant concentration gradients from becoming established. They can also be greatly reduced, as 
shown by Mr. M. N. Dastur and Prof. J. Chipman (Massachusetts Institute of Technology) in a paper dealing specifically with the problem, by the addition of a heavy inactive gas, such as argon, to the mixture.

The present state of our knowledge of solid metallic solutions is rather different from that of liquid solutions. For solid solutions we frequently have a structure which has been determined precisely by X-rays, and an exact knowledge of the conditions under which one structure becomes unstable relative to another. As pointed out by Dr. R. M. Barrer (Bedford College, London), simple spatial considerations, such as the ratio of the radius of the interstitial atom to that of the metal atom, lead to a reasonably clear understanding of the type of structure which will be assumed. In contrast, our knowledge of the chemical potentials of solutes in such solid solutions is fragmentary, to say the least. In the liquid state the reverse is the case ; for, as Prof. Chipman showed, there are now a reasonable number of such solutions for which the thermo. dynamic data are satisfactory. On the other hand, we have no exact model for our liquid solution, and can only suppose that it differs from the solid mainly due to the relaxation of spatial restrictions, brought about by melting. This accounts, of course, for the marked increase on melting in the solubility of substances present as interstitial atoms; but this very relaxation makes it difficult to interpret the marked effect of one solute on the activity of another, as described in the papers by Prof. Chipman and by Dr. J. A. Kitchener, Dr. J. O'M. Bockris and Mr. A. Liberman (Imperial College, London).

From the point of view of process metallurgy, kinetic aspects are mainly of interest at low temperatures in the solid state. At high temperatures, diffusion usually controls the rate for processes involving solids, and convection for those involving liquids. This can readily be appreciated when it is remembered that at $1,600^{\circ} \mathrm{C}$., for example, no less than one collision in $10^{\circ}$ is energetically suitable for an activation energy of 50 kilocalories, as compared with one in $10^{14}$ at $500^{\circ} \mathrm{C}$. The most commonly investigated property of solid solutions is the diffusion of solute atoms in the metal lattice. The property most frequently measured, however, is the movement of the solute through a thin sheet of metal; but this, as Dr. Barrer stressed, is often governed more by surface processes than by lattice diffusion. A good example was provided by Sir Charles Goodeve and Mr. K. H. Jack (British Iron and Steel Research Association), who reported that the slowest step in the evolution of nitrogen from an iron-nitrogen alloy (the $\varepsilon$ phase of the iron-nitrogen system) is the combination of pairs of nitrogen atoms at the surface. In the presence of hydrogen gas, which appears to render this combination process unnecessary, the evolution is $10^{4}$ times faster, and lattice diffusion becomes rate-determining to some extent.

The value of thermodynamics in the design of metallurgical processes was brought out strongly in the section on roasting and reduction. Its application is particularly important in the reduction of refractory oxides for winning such metals as magnesium, titanium and vanadium. A good example was provided by Prof. L. M. Pidgeon and Dr. J. A. King (Toronto), who reported their studies of the equilibrium :

$$
2 \mathrm{MgO}+2 \mathrm{CaO}+\mathrm{Si}(\mathrm{Fe})=\mathrm{Ca}_{2} \mathrm{SiO}_{4}+2 \mathrm{Mg}(\mathrm{g})+(\mathrm{Fe}) .
$$

This is the basic reaction for the Pidgeon process, which was used in Canada during the War for making magnesium from dolomite and ferrosilicon. The pressure of magnesium developed by this reaction at $1,200^{\circ} \mathrm{C}$. is $19 \mathrm{~mm}$., as compared with $1.9 \mathrm{~mm}$. for the reaction,

$$
4 \mathrm{MgO}+\mathrm{Si}=2 \mathrm{Mg}(\mathbf{v})+\mathrm{Mg}_{2} \mathrm{SiO}_{4},
$$

which was investigated in Germany in 1940. The reason for the difference lies, of course, in the far more negative free energy of formation of the calcium than the magnesium silicate.

The method of representation of free energy data is important for those concerned with the extractive processes. Two methods were discussed at the meeting; one the plot of $\Delta G^{\circ}$ against $T$, which was illustrated by Prof. C. W. Dannatt (Royal School of Mines, London) and Dr. H. J. T. Ellingham (Royal Institute of Chemistry, London) in their introductory paper to this section, and the other the plot of $\log K$ against $I / T$, which was used by Dr. M. J. N. Pourbaix and Madame C. Rorive-Boute (Brussels) in describing a series of oxide systems. Although each method has its merits, it would seem desirable to select one as standard, since the graphical representation of collected data is certain to become of increasing importance. In the light of the discussion, the $\Delta G^{\circ}, T$ plot would seem to be of more general application, since it can include data for a wide variety of systems in one diagram. With complex processes this makes it possible to distinguish at a glance the important equilibria from the unimportant, and to see how the systems change as temperature and pressure are altered.

Dr. P. Gross and Messrs. C. S. Campbell, D. L. Levi and P. J. C. Kent (Fulmer Research Institute) reported some interesting work on the thermodynamics of aluminium halides by measurements of the reaction pressures set up by equilibria of the type :

$$
\mathrm{NaCl}_{(\text {(solid) }}+\mathrm{Al}_{\text {(liquid) }}=\mathrm{Na}_{(\text {vapour })}+\mathrm{AlCl}_{\text {(gas) }} \text {. }
$$

Direct measurements of the pressure are not possible on account of the reactive character of the halides, so they had to adopt an unusual experimental technique. The unknown gas-solid equilibrium, together with a known one which does not interfere with it, was allowed to establish itself in an evacuated vessel closed except for a capillary outlet. This outlet served as a slow escape for the equilibrium gas mixture, which was collected in a suitable condenser on emerging from the capillary. The ratio of the unknown pressure to the known was determined by analysis of the condensate, the known pressure in this case being the vapour pressure of the alkali halide.

The primary reactions which occur in roasting and reduction processes were described by Dr. J. S. Anderson (Atomic Energy Research Establishment, Harwell) in terms of the lattice defects which can occur in ionic crystals, and particularly oxides and sulphides. For these materials the stoichiometric compound is a special case, and in general there is either a very small excess of oxygen in the lattice associated with cation holes, or excess of metal as interstitial metal atoms. In the light of this know. ledge the reduction process may be considered as taking place in the following stages. First there is chemisorption of hydrogen or carbon monoxide at the surface as hydroxyl or carbonate ions, as proposed by Garner, the additional valence electrons being accommodated by lowering the valency of one or more cations and thus creating lattice defects in 
the surface. These defects now migrate into the lattice and increase in concentration until saturation is reached, and metal or lower oxide forms as a new phase. In roasting sulphides one would similarly expect that oxygen ions would first be formed on the surface, creating cation holes within the lattice. This would be followed by destruction of the positive holes as oxides of sulphur are eliminated, and the resultant building of oxygen into the lattice in place of sulphur. Studies of the roasting of copper sulphides by a new nethod reported by Prof. E. A. Peretti (Notre Dame, Indiana) are in line with this picture, for they show that the reaction proceeds directly from cupric to cuprous sulphide and finally to cuprous oxide, and not via the formation of sul. phates as previously believed.

Our present understanding of liquid slags is far from adequate. This can be attributed partly to the fact that ionic melts in general have received little attention from the physical chemist, and partly to the great difficulties which arise in making controlled experiments with materials which attack containers of all types. As Dr. F. D. Richardson (British Iron and Steel Research Association) pointed out, our ideas of liquid slag structures are based essentially on our knowledge of the structures of crystalline silicates, phosphates and aluminates, and the recognition that the liquid state differs from the solid mainly in lacking any long-range order. This picture is corroborated by X-ray work on silica glasses, which have been shown to consist of random networks of silicate tetrahedra with metallic cations located in the holes between them. The chemical potentials of the components of slags have in some cases been determined by slag-metal equilibrium measurements. For binary systems they can be obtained less directly from phase diagrams, and interesting results derived in this way were reported by Prof. M. Rey (École des Mines, Paris). The standard states for some of the oxides and sulphides of importance in slags present a problem in cases such as ferrous oxide ( $\mathrm{FeO}$ ) and iron sulphide ( $\mathrm{FeS})$, which can exist over wide ranges of composition depending on the equilibrium oxygen or sulphur pressures. Although failure to take account of such non-stoichiometric variations may not lead to large errors in total free energy changes, it was stressed by Dr. G. M. Willis (Melbourne) that large errors may be caused in the partial molar free energies of com. ponents in slag melts. An ionic view of slags has been developing in recent years, and although, as Prof. E. A. Guggenheim (Reading) pointed out, it is irrele. vant, so far as slag-metal equilibria are concerned, whether the various atoms or atom groupings are ionized or not, knowledge of the ionic constitution is helpful in developing a detailed model of slag melts, and may, indeed, be of practical importance in arc furnaces. Dr. J. A. Kitchener, Dr. J. O'M. Bockris and Messrs. J. Tomlinson and S. Ignatowicz (Imperial College, London) reported measurements of the electrical conductivity of binary silicate melts, which indicate that the conduction is mainly ionic. It increases more than one-hundredfold at the melting point for calcium and manganese silicates, and shows a temperature coefficient compatible with the view that the conductivities are due to the small, relatively mobile cations, and the viscosities to the large, relatively immobile anions.

All those concerned with the application of physical chemistry to process metallurgy owe a great debt to the Faraday Society for arranging this discussion.
Apart from the stimulating effect of bringing together workers in this field from many laboratories and many different countries, it has brought the criticisms and ideas of physical chemists outside this field to those who are now working in it. It is to be hoped that the discussion will also stimulate physical chemists generally to take a new interest in the fundamentals of some of these interesting high. temperature systems.

F. D. RICHARDSON

\section{VETERINARY EDUCATION : DEVELOPMENTS AT CAMBRIDGE}

\section{By Dr. JAMES T. EDWARDS}

$\mathrm{T}$ HE address before us* breathes a freshness of outlook which bestirs the imagination of those who have watched a public awakening into the need for finding a healthy solution to a problem which, since the onset of the Industrial Revolution, and even before then, has been treated in Great Britain, to its sad discredit, with sore neglect.

This problem is concerned not only with the 'doctoring of animals', the pursuit which the ordinary member of our public associates with the designation 'vet.'. That in itself, it can never be too strongly emphasized, is an art which calls forth all the skill that is born of long and close experience, all the powers of keen and careful observation, and all the moral virtues of sympathy and kindliness which the human faculties can muster. It is an art which in the course of its long history has seen its periods of great triumph and of respect in the eyes of society, and its periods of utter debasement. Its triumphant periods have been within the histories of great empires at the height of their glory-the Buddhist, the Byzantine, and the Arab; and, let us hope, the British Commonwealth, as it is now marching to higher destiny, will be added to them. One of the worst, if not the worst and most infamous, of the periods in which the art suffered degradation was that in which the Church dominated thought and conduct in the Western world-the Dark Ages. Let us insist at once that this decline in respect for the art did not owe its origin to the Christian ethic, with its dominant note of 'charity'. Compounding for it a doctrine in which the ingredients were not incompatible with persisting Mediterranean cults and contained an infusion of neo-Platonism with some tincture of Christianity, the early Church Fathers, in their wisdom, shrewdly mindful of means of fostering moral uplift among peoples as they were at that time, founded a powerful hierarchy. This hierarchy increasingly in its interest played hard on the Platonic concept of the 'soul' as a higher state of being, which was immortal, and did not pertain to the 'beasts', which in their suffering were therefore denied both pity and mercy. (This theme has been well developed recently by the eminent French scholar and experienced veterinarian Emmanuel Leclainche in his book, "Histoire de la Módecine Vétérinaire" (Toulouse : Office du Livre, rue Alsace. Lorraine, 42 ; 1936).) The human physicians were hence eagerly absorbed into the Church, and their learning became that of the Church, disdaining craftsmanship and the knowledge which Plato's

- Veterinary Education. An Inaugural Lecture. By Prof. W. I. B. Beveridge. Pp. 40. (Cambridge: At the University Press, 1948.)
18. 6d. net. 